\title{
La fe de Cristo
}

\author{
Antonio González, F. \\ Centro de Reflexión Teológica, \\ San Salvador, EI Salvador.
}

\section{Introducción}

El objetivo de este trabajo es obtener una ciera clarificación sobre cl significado de la fe en la teología paulina. En este sentido, su interés primero es más sistemático que exegético, si bien en este estudio consideraré más bien cl aspccto exegćtico de la cuestión. Por supuesto no se pretende aqui abarcar el tema de la teología paulina de la fe en toda su amplitud. Se trata solamente de estudiar una paric del problema: el significado de la expresión pístis lesoû Christoū en Pablo y sus implicaciones tcológicas.

\section{Presentación del problema}

La expresión pístis lesoû Christoû o bien pístis toû hyioû toû Theô̂ es utilizada seis veces en el corpus paulinum (Gal 2, 16;2, 20; 3, 22; Flp 3, 9; Rm 3, 22, 3, 26; también E[ 3, 12 y $1 \mathrm{Tm} 3,13$ ). La traducción habitual de estos pasajes suele ser "la fe en Criso Jesús" (o también "la fe en el Hijo de Dios")', es decir, se entiende lesoû Christoû como un genitivo objetivo que enuncia cuál es el objelo de esa fe: Jesucristo.

Sin embargo, en griego es posible otra traducción: se puede entender pístis lesoû Chrisıoú como "la fe de Jesucristo". Aqui se interpreta la expresión como genitivo subjetivo, es decir, según esta traducción para Pablo no serfa primariamente Jesucristo en estos pasajes el objeto de la fe, sino el sujeto de la misma. Lo que se subrayaría no sería nuestra fe en él, sino la fe que él mismo tuvo. Esto implica naturalmente un cambio profundo de la interpretación tcológica de estos textos, cuya relevancia para la comprensión global de la teología paulina y neotestamentaria no es en absoluto despreciable. 


\section{Relevancia teológica del problema}

La misma posición de varios de los textos cilados subraya su importancia teológica: Gálatas 2, 16; 2, 20; Romanos 3, 22; 3, 26 tienen una función clave en las respectivas cartas: están situados justamente como formulación de la propositio o tesis principal de Pablo. Este hecho, unido a la importancia sistemática que tienen Gálatas y Romanos en la teología paulina deberían hacemos ya sospechar que la fómula pistis lesoû Christoû quiere expresar algo central de la misma.

a) La cuestión de la justificación. Esta sospecha queda confirmada cuando atendemos al contenido de los pasajes citados. Justamente en seis de ellos Pablo está afirmando la llarnada "justificación por la fe": no las obras vanas de la ley, dice Pablo, sino la pístis lesoû Chrisıoù es aquello que nos redime y libera. La expresión pístis lesoû Christoû contienc precisamente la respuesta paulina a la cuestión de la justificación, que constituye una de las claves fundamentales para enfocar correctamente el problema de la gracia.

La traducción habitual de los pasajes como "fe en Jesucristo" (genisivo obje(ivo) destaca el papel de la fe personal en la justificación. La comprensión tradicional de estos textos conviene en señalar que el hombre no es justificado por la actividad externa y convencional de la ley, sino mediante la le individual e interna. Ciertamente esta interpretación tiene la ventaja que contiene una liberación de las convenciones legales en favor de la propia responsabilidad. Pero no se ve aqui cómo desde tal perspectiva se puede explicar la iniciativa de Dios en la justificación, a no ser que se convierta a la fe por la que nos justificamos en un instrumento o condición de tal iniciativa divina

Ciertamente, la justificación por la fe supera la mentalidad de los méritos externos alcanzados por las obras de la ley, pero la sustituye por una especie de mérito interno: la fe personal. La fe puede ser entendida como una disposición psíquica, como por ejemplo en los círculos pietistas, como un adhesión intelectual a determinadas verdades, como en la teología católica anterior al Vaticano II, o también como una especie de decisión existencial, como es el caso de Bultmann y de muchas teologías contemporáneas. En todos estos casos, la fe que nos justifica aparece como una actividad (sin duda interior) del hombre? igual que las obras (éstas exteriores) de la ley. La libre y gratuita iniciativa de Dios, que Pablo quiere destacar, como después también los reformadores, parece terminar por disolverse en una mera distinción entre el ámbito interno y externo del hombre y su acción.

Claro está que se podría decir con A. Schlatter que la fe no es un mérito propio, sino "la obra de Jesús en nosotros"3, un verdadero regalo de Dios. Pero el problema está en que, en último término, se podría decir lo mismo de la ley. Además habría que preguntarse si tal concepción de la fe se puede encontrar 
efcctivamente en Pablot.

b) El papel de Cristo en la salvación. En cualquier caso, si se entiende pístis lesoû Christoû como "fe en Jesucristo", el papel de Cristo en la salvación es difícil de explicar teológicamenlc, al menos en principio. En tal concepción, Cristo es ante todo el objeso de mi fe. Su aclividad sal vífica queda en un segundo plano, de tal manera que pareciera que es la accividad del hombre en cuanto creyente la que realiza la salvación, y no Cristo mismo. Como el mismo Ebeling señala, en tal concepción de la fe no es fácil aclarar la relación constitutiva entre cristología y soteriologias.

c) EI Jesús histórico. Hay que referirse también a la constatación, muy unida a la anterior, de que la traducción como genitivo objetivo ("Ce en Jesucristo") conlleva el peligro de dejar fuera de consideración el papel del Jesús histórico en la salvación. Si Jesús es ante todo cl objeto y no el sujeto de la fe, quien de modo directo resulta relevante para la economía de la salvación es el Cristo resucilado. A lo sumo sería relevante para la fe el mensaje del Jesús histónico, incluso podría éste ser considerado como objeto de la le, con el consiguiente peligro de que ésta sea moralizada. Pero no se ve en qué sentido la historia y la praxis de Jesús de Nazaret sea de modo directo relevante para la fe: solamente se podría decir que aquél en quien creemos (el Cristo) es el mismo que el Jesús histórico por medio de una interpretación a posteriori. Pero si bajo pístis lesoû Chrisıoû (Pablo menciona explícitamente a Jesús) se entiende "la fe de Jesucristo", entonces la historia de Jesús y de su fe juega un papel central para nuestra salvación: su fe es justamente lo que nos ha justificado. Ciertas presentaciones de la teología de Pablo, según las cuales éste solamente estaría interesado en el Cristo resucitado descansan probablemente (al menos en parte) en este problema de traducción.

d) La dimensión social de la fe. Otro problema teológico, relacionado con lo anterior, es el que toca a las dimensiones sociales e históricas de la fe. El filosofo judio Martin Buber ha distinguido entre la amunah hebrea, cargada de significado comunitario, histórico y ético, y la pístis paulina, que sería según él algo meramente individual, subjetivo y psíquico ${ }^{6}$. Es claro que aquí Buber presupone la traducción tradicional de pístis Iesou Christoû como genitivo objetivo: la fe cristiana serfa una fe individual del creyente en Cristo y carecería de toda dimensión social e histórica.

Ahora bien, si en lugar de "la fe en Cristo" se traduce "la fe de Cristo", la cuestión toma un cariz totalmente distinto: esa fe que según Pablo nos justifica es la fe de un creyente judío (Jesús). Pero, sobre todo, si la fe de Jesucristo nos salva, nuestra vinculación comunitaria y nuestra continuidad histórica con su fe es decisiva para la justificación'. Con esto no se convertiría la pistis paulina en un mero equivalente de la amunah veterotestamentaria, pues Pablo no habla de la fe en general, sino de una fe muy concreta: la de Jesús, la cual determinaría 
de modo radicalmente nuevo lo que se ha de entender por fe después de él. Pero las dimensiones sociales e históricas de la amunah estarian también presentes en ella ${ }^{\mathrm{a}}$.

\section{Anotaciones sobre la historia del problema}

Hemos visto que la traducción correcta de la expresión pístis lesoû Christoû es especialmente relevante para varias cuestiones teológicas fundamentales. ¿Qué condicionamientos históricos están detrás del hecho de que hoy prevalezca, en general, el genitivo objetivo a la hora de traducir estos textos centrales?

a) Las traducciones antiguas. Las primeras traducciones del Nuevo Testamento han entendido inequívocamente "la fe del Mesías". Así, por ejemplo, la Peschilla siria". Las traducciones latinas y más tarde la Vulgata tradujeron fides Jesu Christi. Sin embargo, esto no es, en latín, un criterio dirimente: el genitivo latino puede ser tanto subjetivo como objetivo. En favor del genisivo subjetivo habla el hecho de que en Gálatas 2,16 la Vulgata mantiene claramente la diferencia entre credimus in Christo y fides Christi, la cual en Lutero desaparece completamente ${ }^{10}$. Lutero fue de hecho el primero en la edad modema que tradujo los mencionados pasajes como Glaube an Jesus Christus ("fe en Cristo"). La tendencia de los reformadores a subrayar lo decisivo de la fe del creyente para su salvación ha jugado sin duda un papel importante en esta opción del traductor. Sin embargo, entre los mismos reformadores no había unanimidad en este punto: la traducción española de Casiodoro de la Reina (1602) entendió la fe de Cristo, e igualmente la Authorized Version inglesa (1611) traduce the faith of Christ, con la sola excepción de Romanos 3, 26.

b) Prejuicios dogmáticos. Se puede sospechar que la tendencia general actual al genitivo objetivo descansa sobre presupuestos teológicos, que inevitablemente condicionan el trabajo exegético y conducen a determinadas opciones, de modo consciente o inconsciente. Con esto no me refiero solamente a la teología luterana de la fe, sino también a la tradición escolástica Para Tomás de Aquino es impensable que Jesucristo haya tenido fe, porque Cristo desde su generación disfruta de la visio de Dios. Para la escolástica la fe es solamente necesaria cuando hay una falta de conocimiento, y esto es imposible en el caso del Logos etemo".

c) La discusión actual. Solamente en los últimos aflos se ha abierto por diversos motivos la discusión sobre la "fe de Cristo". Por una parte, muchos de los prejuicios teológicos y confesionales han desaparecido, de modo que la fe de Cristo es un tema usual en las cristologías actuales ${ }^{12}$, y también en la teología de la liberación ${ }^{13}$. La exégesis, por su parte, se ha planteado también la cuestión de la lectura correcta de la expresión pistis lesoû Christoú. Aunque en el Nuevo Testamento hay otros pasajes que se pueden aducir para hablar de la fe de Cristo (por ejemplo, Hb 12,2), la discusión "por los motivos que ya se han menciona- 
do" es especialmente importante cuando toca a la teología de la fe y de la justificación de Pablo. Ya J. Hausleiter se hizo la pregunta de la pístis lesoû Christoû en $189 \mathrm{l}^{14}$. Su iniciativa fue continuada y radicalizada por G. Kittel's, quien levantó muchas voces críticas.

En los años cincuenta A. G. Herbert y T. Torrance, bajo cl influjo de la teologla de K. Barth, defendieron de nuevo el genirivo subjetivo. Según su opinión, lo que Pablo quiere decir últimamente es que la fidelidad de Dios (su amunah) se ha hecho carne en Cristo ${ }^{16}$. Según G. M. Taylor se trata más bien de una metáfora jurídica: pistis serla aquí la traducción griega de la institución romana del fidei commisum y según esto Cristo sería para Pablo el albacea de la herencia judia, ahora entregada a los gentiles ${ }^{17}$. Los nuevos métodos exegéticos han sido también introducidos en esta discusión: para R. B. Hays el centro de la teología paulina es una historia, la cual está presupuesta en la epístola a los Gálatas como una predicación ya sucedida. Esta "subestructura narrativa" podría ser descubierta con la ayuda de la semántica estructural. El paralelismo de la estructuras narrativas en Gálatas 4, 3-6 y 3, 13-14 y la aplicación del modelo de Greimas mostraría que pistis no es en estos textos una propiedad de los creyentes, sino más bien una "ayudante" (una propiedad) del "héroe", que en este caso es Cristo. Esta hipótesis sería confirmada mediante el análisis de la expresión pístis Iesoû Christoû en Pablo y por su contribución al esclarecimiento de la lógica narrativa de Gálatas 3, 1.4, $11^{11}$.

En lo que sigue, no quisiera entrar en el análisis estructural de un pasaje determinado, sino simplemente considerar de modo breve los textos en los que aparece la expresión pístis lesoû Christoû, aludiendo a los principales motivos en favor de un genitivo subjelivo.

\section{Consideraciones exegéticas}

5.1. Observación general. La traducción de pístis lesoû Christoû como "fe de Jesucristo" parece en principio la más inmediata, aunque sólo sea por la siguiente razón: en el Corpus Paulinum se emplea pistis con genitivo de persona veinticuatro veces, además de en los textos donde se habla de la pístis Christoû. En veinte ocasiones se trata de la fe de cristianos, dos veces se refiere el texto a la fe de Abraham, una vez a la fidelidad de Dios', y en otra ocasión a alguien, "un caso general" a quien la fe se le cuenta como justicia (Rm 4, 5). Por tanto, prescindiendo del caso en disputa, hay que decir que la expresión pístis + genitivo es usada por Pablo siempre en el sentido de un genitivo subjetivo. Esto ya seria suficiente para establecer que la carga de la prueba recae más bien sobre quienes quieren leer ahí un genitivo objetivo. En los LXX y entre los judíos helenísticos no era frecuente el uso del genitivo objetivo, sino que para ello utilizaban una preposición. Cieramente, hay algunas excepciones, incluso en el Nuevo Testamento (por ejemplo en Mc 11, 22), Pero jamás en Pablow, a 
no ser que alguno de los textos donde aparece la expresión pistis lesou Christou diera pie para esta lectura. Veamos entonces los textos en particular.

5.2. Gal 2, 16: "conscientes de que el hombre no se justifica por las obras de la ley sino por la pistis lesoû Christoû, también nosotros hemos creído en Cristo Jesús (eis Chrisıón Iesoûn episteúsamen), a fin de conseguir la justificación por la pistis Chrisioû, y no por las obras de la ley, pues por las obras de la ley nadie será justificado".

Según la estructura de Gálatas que propone H. D. Betz estaríamos aqui justamente ante la propositio, destinada a exponer la tesis principal de la carta (Gal 2, 15-21). Sin embargo, Betz piensa que eis Christón lesoûn episteúsamen (aquí hay que traducir sin duda "hemos creído en Cristo") es una aclaración de "por la pístis Iesoû Christoû́ ${ }^{21}$. Pero si así fuera, parecería una tautología bastante inútil utilizar la expresión "fe en Cristo" tres veces en el corto espacio de un mismo versículo22. Cuando Pablo introduce, junto con el genitivo usual, la construcción eis + acusativo, ello pareciera querer indicar más bien que lo que quiere hacer es sentar una diferencia entre la fe de Cristo y la fe de los cristianos en él ${ }^{23}$.

5.3. Gal 2, 20: "y no vivo yo, sino que es Cristo quien vive en mí; la vida que vivo al presente en la came, la vivo en la pístis toû hyioû toû Theoû que me amó y se entregó a sí mismo por mi".

Este versículo está también dentro de la propositio de la epistola. En él se plantea la importante pregunta por la participación diaria de los cristianos en la muerte y la resurrección de Jesucristo ${ }^{2 n}$. El contenido teológico que se juega al oplar por una u otra traducción es el siguiente: si traducimos pístis roû hyioû tồ Theoû como un genitivo objetivo, la participación del cristiano en la vida y muerte de Jesucristo es primariamente intencional: por mi fe tomo parte en su cruz y en su resurrección. Si por el contrario leemos aquí un genitivo subjetivo, la tesis de Pablo cobra un aspecto lotalmente distinto: por mi morir y resucirar acıual tomo parte en la fe de Cristo que se entregó por mí. Mi participación es según esto no puramente intencional, sino una incorporación real e incluso física al misterio pascual de Jesucristo.

Y esta interpretación encaja mucho mejor en el contexto inmediato: Pablo subraya enfáticamente en el versículo 19b su morir real con Cristo ("con Cristo estoy crucificado"). Si ahora en el versículo 20 dijera que este "con-morir" es algo que solamente sucede "en la fe", estariamos ante una suavización de su tesis. Si por el contrario lo que dice es que su morir y resucilar diarios son una participación en la fe de Jesucristo, tendríamos una perfecta continuidad lógica en la argumentación paulina.

R. B. Hays ha señalado como otro motivo para esta interpretación el paralelo en Romanos 5, 15:

Digitalizado por Biblioteca "P. Florentino Idoate, S.J."

Universidad Centroamericana José Simeón Cañas 
Romanos 5, 15: "en la gracia de un solo hombre, Jesucristo..." Gálatas 2, 20: "en la fe del Hijo de Dios..."

La gracia en Romanos 5, 15 es aquella que viene de Cristo (genîtivo subjetivo), y no simplemente mi propia gracia (genitivo objetivo) ${ }^{23}$.

5.4. Gálatas 3, 22: "Pero, de hecho, la Escrimra encerró todo bajo el pecado, a fin de que la Promesa fuera otorgada a los creyentes ('a los que tienen fe') mediante la pistis lesoû Christoû".

Si Pablo hablara aqui dos veces sobre nuestra propia fe, se trataría, como en Gálatas 2,16, de una repetición innecesaria (la promesa en base a la fe en Cristo se daría a los que creen en Cristo...). Si la promesa fuera dada simplemente por nuestra fe en Jesucristo, no queda nada claro qué papel juega aquí el ejemplo de Abraham, pues él no ha creído en Cristo. Además, si entendiéramos pístis lesoû Christoû como un genitivo objelivo, el rol de Crisı en la justificación aparecerfa en este texto como puramente pasivo: él sería simplemente el objeto de nuestra fe. Pero, ¿no encaja mejor en el contexto pensar que Jesús, por su fe "hasta la muerte" fue justificado y solamente después vendría nuestra justificación "por la fe", como participación en su fe? Este punto de vista enlazaría perfectamente con el tema paulino del papel salvífico de la obediencia de Cristo como representante de la humanidad ( $R \mathrm{~m} 5,19)$ : no hay que olvidar que obediencia y fe son términos casi idénticos en Pablo'o

5.5. El párrafo Gálatas 3, 1-4, 7. Desde la perspectiva de lo dicho en Gálatas 3, 22 se puede entender el uso de pístis en todo el párafo Gálatas 3, 14. 7, que según Betz constituye la probatio de la carta:

a) "ex akoês piste6s" (versículos 3,2 y 3,5) no tiene que ser necesariamente interpretado como "por el oír con fe" o "por el oír, que hace posible la fe". En primer lugar, akoé significa más bien "predicación" o "anuncio" (cfr. Rm 10, 16-17) ${ }^{2}$. Por otra parte, pístis tiene aquí un sentido distinto que en Romanos 10, 17: alí se trata de la fe de los cristianos, mientras que en Gálatas se trata de la llegada histórica del cristianismo. Akoé písteôs significa por tanto "la predicación o el anuncio de la fe" (de Cristo y por tanto también de los cristianos).

b) "el juslo vivirá por la fe" (versiculo 3, 11). Según R. B. Hays ${ }^{23}$ es posible aquí una interpretación cristológica. Como "justo" no se alude aquí primariamente a cada cristiano, sino ante todo al Mesías. Y es que los LXX posibilitaban (contra el original bebreo) una interpretación mesiánica de Habacuc 2, 3-4 como un discurso sobre el "el que vendrá" (Ha 2, 3). Por otra parte, Hebreos 10, 38 y algunas versiones de los LXX leen aquí "mi justo". Mientras en el texto masorético y también 1QpHab (Qumrán) dicen claramente "vivirá por su fe" (bacemunato), y los LXX traducen "mi fe" (písteôs mou), Pablo deja el sujeto de la fe abierto. Según Hays es posible que aquí Pablo se 
separc de los LXX para con ello aludir a la fe de Cristo. A mi modo de ver, Pablo habría podido decir simplemente "su fe". Por eso me parece más probable que utilice conscientemente la expresión ek písteôs de un modo general, para referirse simplemente al "principio-fe" ( $c f r$. los versículos 7.8.9.12 del capítulo 3 ), siendo Jesucristo el origen de tal principio (efr. los versículos 22.24 , y también el versículo 14), muy en la línea de lo que dice Hebreos 12, 2.

c) Gálatas 3, 26 no habría de ser entonces traducido como "todos son hijos de Dios por la fe en Jesucristo", sino más bien "todos son hijos de Dios en Jesucristo por la fe", o incluso "hijos de Dios por la fe", pues la preposición para expresar en griego la fe en alguien no es en sino eis. Otra lectura válida sería entonces también "lodos son hijos de Dios por la le que está en él" (presente y fundada).

d) En Gálatas 3, 23.25 menciona Pablo "la venida de la fe". Aquí la fe parece ser un fenómeno histórico supraindividual. Según R. B. Hays ${ }^{29}$ hay en 3, 23-29 un paralclismo narrativo con 4, 3-7, con lo que la venida de la pistis sería prácticamente idéntica con la venida de Cristo. Un motivo más para el genitivo objetivo.

e) Sobre el párralo en su conjunto habria que decir lo siguiente: la comprensión paulina de la fe en el mismo tiene la fe de Abraham como modelo. Pablo considera a Cristo la descendencia de Abraham ( $c f r$. Gal 3, 16): si no queremos entender esto como una mera observación genealógica, sin mucho sentido por cierto, habria que decir que la continuidad entre Abraham y Cristo está justamente en su fe: según eso, Abraham no sería simplemente un modelo para los creyentes, sino ante todo un predecesor de Cristo. Si hay un paralelismo entre ambos, es lógico que éste consista en la fe, dado que ésta es para Pablo la principal propiedad de Abraham ${ }^{30}$.

5.6. En Romanos 3, 21-26 la expresión aparece recurrentemente: (Rm 3, 21:) "Pero ahora, independientemente de la ley, la justicia de Dios se ha manirestado, atestiguada por la ley y los profelas, ( $R$ m 3, 22:) justicia de Dios pístis lesoû Chrisıou. para todos los que creen - pues no hay diferencia alguna; (Rm 3, 23:) todos pecaron y están privados de la gloria de Dios- $(\operatorname{Rm} 3,24:)$ y son justificados por el don de su gracia, en virtud de la redención realizada en Cristo Jesús, (Rm 3, 25:) a quien exhibió Dios como instrumento de propiciación por la fe en su sangre, para mostrar su justicia, habiendo pasado por alto los pecados cometidos anterionmente, $(\operatorname{Rm} 3,26$ :) en el tiempo de la paciencia de Dios: en orden a mostrar su justicia en el tiempo presente, para ser él justo y justificador del que procede de la pistis lesoû". Los motivos para un genitivo subjetivo son los siguientes:

a) En el resto de Romanos es siempre Theós el objeto de la fe, y no Cristo.

b) En el contexto aparece pístis solamente con genilivos subjetivos: pístis

Digitalizado por Biblioteca "P. Florentino Idoate, S.J."

Universidad Centroamericana José Simeón Cañas 
Theoû (la fidelidad de Dios, cfr. $\operatorname{Rm} 3,3$ ) y la fe de Abraham (pístis Abraám, en $\operatorname{Rm} 4,12.16$ ).

c) El paralelismo que aparece más adelante entre "de la pístis lesoû" $(3,26)$ y "de la fe de Abraham" $(4,16)$ habla también a favor del genitivo subjetivo.

d) En caso de interpretarse como genitivo objetivo, tendriamos en 3, 22 una nueva reduplicación, ya que tanto pístis lesoû Christoû como "los que creen" (pisteúontas) se referirian a la fe de los cristianos.

e) Según 3, 22 se ha revelado ahora la justicia de Dios. Es bastante sensato pensar que la justicia de Dios se manifestó mediante la fe de Jesucristo (Hijo de Dios) y no por nuestra fe ${ }^{31}$.

f) Con genitivo subjetivo es más fácil entender Romanos 3, 25: No sería "propiciación en su sangre, efectiva por la fe" (como proponen algunas traducciones $^{32}$ ), sino simplemente "propiciación por su fe hasta la muerte".

5.7. Filipenses 3, 9: "y ser hallado en él, no con la juslicia mía, la que viene de la Ley, sino la que viene por la pístis lesoû Christoû, la justicia que viene de Dios, apoyada en la fe".

Para M. D. Hooker ${ }^{33}$ el contexto de este texto es el "canje" entre el creyente y Cristo (2, 5-11 y 3, 20-21; cfr. 1Co 5, 21; 8, 9), que es también el "canje" de la justicia que viene de la fe. El punto de partida es la fe de Cristo, pero habría aquí (y en otros textos) una referencia a la le de los creyentes como respuesta.

\section{Consecuencias teológicas}

Si la hipótesis considerada aquí es correcta, podremos sacar algunas consecuencias para las cuestiones teológicas que planteamos al principio:

a) El fundamento de la justificación no es primariamente nuestro acto interior de fe, sino la fe de Cristo. La justificación por la fe de Cristo es la tesis fundamental de Pablo y ella permite preservar (contra la misma interpretación luterana de estos textos) el interés fundamental de los reformadores: la iniciativa en la salvación viene de Dios por medio de Crisb y no de nosotros.

b) Hay por lo tanto una conexión esencial entre la cristología y la soteriologia, pues la fe de Cristo es el fundamento de nuestra justificación.

c) Recíprocamente, la historia concreta de Cristo y la historia de su fe tiene una función decisiva para nuestra salvación.

d) La fe de los cristianos (en Cristo mismo, pues esto en ningún momento es negado por Pablo) ha de ser entendida como respuesta de los cristianos. Esta respuesta consiste ante todo en la participación en su fe (vida en Cristo). Esta participación ha de tener dimensiones sociales e históricas, para poder asegurar la continuidad con su fe concreta. Esto no excluye la dimensión individual de la 
fe, sino que la incluye positivamente.

e) Los pasajes que hemos considerado (sobre todo Gal 2, 20) muestran también que la fe de Jesús se muestra primariamente en su entrega concreta en la cruz. La cruz no es por tanto un mero símbolo religioso aislado al que el creyente dirige su fe subjetiva y justificante, sino el acontecimiento justificador en cuanto tal. El "morir y resucitar" de los cristianos actualmente es justamente la participación en la enırega justificante y confiada de Cristo.

\section{Notas}

1. Cfr. la Nueva Biblia Española, la Biblia de Jerusalén y la traducción de CanteraIglesias.

2. Cfr. R. B. Hays, The Faith of Jesus Christ. An Investigation of the Narrative Subestructure of Galatians 3:1-4:/1, Chico, Califomia, 1983, p. 139.

3. Cfr. A. Schlatter, Der Glaube im Neuen Testament, Stuttgart, 1963, p. 382.

4. Cfr. R. B. Hays, op. cit., p. 140.

5. Cfr. R. B. Hays, op. cit., p. 139.

6. Cfr. M. Barth, "The Faith of the Messiah", The Ileythrop Journal, 10 (1969), pp. 363-370.

7. Por esto al hablar de la fe sería constitutiva una referencia a la Iglesia en cuanto medio de esta continuidad: no se trataría de la acostumbrada dialúctica entre fe individual y autoridad eclesial, sino de una fe que, por definición, es eclesial.

8. Sobre las dimensiones sociales e históricas de la experiencia de Dios en general, puede verse X. Zubiri, El hombre y Dios (Madrid, 1984).

9. Cfr. G. Howard, "On the 'Faith of Christ", Harvard Theologiscal Review, 60 (1967), p. 460.

10. Cfr. G. Howard, ibid., pp. $460-461$.

11. Cfr. Tomas de Aquino, Summa Theologica, II, q. 7, a. 3.

12. Cfr. G. Ebeling, "Jesus und Glaube", en Wort und Glaube, Tubinga, 1962, pp. 203 254; J. Moltmann, Der gekreuzigte Gott. Das Kreuz Christi als Grund und Kritik christlicher Theologie, Munich, 1972; W. Pannenberg, Grundzüge der Christologie, Gutersloh, 1966 (2' edición), pp. 203-204; C. Duquoc, "La esperanza de Jesús", Concilium, 59 (1970), pp. 1089-1096; W. Thusing, "Neutestamentliche Zugangswege zu einer transzendental-dialogischen Chriscologie", en K. Rahner-W. Thising, Christologie-dogmatisch und eregetisch, Freiburg i. B., 1972, pp. 211-226.

13. Cfr. L. Boff, Jesucristo el libertador. Buenos Aires, 1974, p. 124.; J. Sobrino, Cristologla desde América Latina, México, 1977 (2 edición), pp. 59-108. 
14. Cfr. "Der Glaube Jesu Christi und der christliche Glaube", NKZ, 2 (1891), pp. 109145; 205-230. Sobre el origen y el desarmollo de la discusión exegética cfr. G. Howard, "The Faith of Christ", Exp.Tim., 85 (1974), pp. 212-215; también R.B. Hays, op. cil., Pp. 158-164.

15. Su posición extrema no es muy sostenible: Kittel intentaba probar que incluso eis Christón lesoûn episteúsamen (Gal 2,16) habría de ser traducido corno "crcímos según Jesucristo", cfr. "Pístis lesoû Christoù bei Paulus", TSK, 79 (1906), pp . 419 436.

16. Cfr. A. G. Herbert, “'Faithfulness' and 'Faith"”, Theology, 58 (1955), pp. 373-379; T. Torrance, "One Aspect of the Biblical Conception of Faith", Exp.Tim., 68 (1957), pp. 111-114.

17. Cfr. "The Function of pisfis Christoû in Galatians", JBL, 85 (1966), pp. 58-76. Otras posiciones en G. Howard, "On the Faith of Christ", op. cit., pp. 462-465.

18. Cfr. R. B. Hays, op. cit., passim.

19. Cfr. Rm 3,3 (y tal vez también $R m 1,17$ ). Prescindiendo de los textos aquí considerados (genitivos de persona siguiendo a pistis) no hay que olvidar que la le en Pablo puede tener muy distintos sujelos y objetos: pistis de Dios a los hombres $(\operatorname{Rm} 3,3$; $\operatorname{Rm} 1,17$ ?); de los hombres a los hombres (Rm 1, 12; Gal 5, 22; 1Ts 3, 2-7); de los hombres a Dios o a Crislo (Rm 5, 2; 1Ts 1, 8; Flm 5).

20. Cfr. G. Howard, "On the Faith of Christ", op. cir., pp. 459-60; y también R. B. Hays, op. cis., pp. $163 \mathrm{~s}$.

21. Cfr. H. D. Betz, Galatians, Philadelphia, 1979, p. 118.

22. Puede verse lo farragosa que resulta la traducción de Lutero de este pasaje.

23. Cfr. G. Howard, "On the 'Faith of Christ", op. cit., p. 460.

24. Cfr. N. Baumert Täglich Sterben und Auferstehen. Der Literalsinn von 2 Kor 4, 12 5, 10, Munich, 1973, $462 \mathrm{pp}$.

25. Cfr. R. B. Hays, op. cir., p. 168.

26. Cfr. R. B. Hays, op. cir., pp. 164-167; también M. Barth, op. cil., Pp. 366-367.

27. Cfr. también R. B. Hays, op. cis., pp. 146ss.

28. Cfr. ibid., pp. 151-157.

29. Jbid., pp. 228-232.

30. M. Berth menciona todavía otros motivos: la amunah en el Antiguo Testamento es justamente la confianza que despierta el rey fiel, que como representante del verdadero Israel (es lo que designa el título de Christós en Pablo) ha de traer la salvación (cfr. M. Barth, op. cis. pp. 365-7). Por otra parte, Pablo contrapone en otros pasajes de la epístola a los Gálatas dos principios: la justificación por la obras de la ley y la justificación "en Cristo" (cfr. Gal 2, 17; también 2, 21 y 5, 4): hemos sido justificados por Cristo (y por tanto por su fe) y no primariamente por nuestra propia fe ( $c f r$. M. Barth, op. cit., p. 368). 
31. Cfr. R. B. Hays, op. cir., pp. 170ss.

32. Por ejemplo, la Einheitsüberserzung alemana.

33. Cfr. su artículo "Pistis Christoû" (Cambridge, 1978). 